\title{
Outcomes associated with Hydroxychloroquine and Ivermectin in hospitalized patients with COVID-19: a single-center experience
}

\author{
Roberto Muniz Ferreira ${ }^{1,2 *}$ (1), Renata Wanderley Beranger $^{1}$ (1), \\ Pedro Paulo Noguères Sampaio ${ }^{1,2}$ (1), João Mansur Filho ${ }^{1}$ (1), \\ Ricardo Antônio Correia Lima ${ }^{1,3}$
}

\begin{abstract}
SUMMARY
OBJECTIVE: Hydroxychloroquine and Ivermectin are advocated as potential treatments for coronavirus disease 2019 (COVID-19) despite the lack of supportive clinical evidence. In this study, outcomes associated with Hydroxychloroquine and/or Ivermectin were determined in a series of patients with confirmed COVID-19 from a single institution in Brazil.

METHODS: Consecutive patients admitted between March and July 2020 were retrospectively analyzed and divided into four treatment categories: no treatment (Group 0), Ivermectin only (Group I), Hydroxychloroquine only (Group II), and Hydroxychloroquine and Ivermectin (Group III). Intensive care unit admission, mechanical ventilation, and death were compared between the Groups.

RESULTS: A total of 230 patients were included, with the following treatment distribution: $35.2 \%(0), 9.1 \%$ (I), $48.3 \%$ (II), and $7.4 \%$ (III). Groups I, II, and III had the higher rates of Intensive care unit admission, mechanical ventilation, or death (0: $23.5 \%$ versus I: $38.1 \%$ versus II: $37.8 \%$ versus III: $70.6 \%, p=0.002$ ), and the greatest mortality was found in Group III (0 versus III: $13.6 \%$ versus $35.3 \%, p=0.03$ ). In the multivariate analysis, Hydroxychloroquine remained significantly associated with death $(\mathrm{OR} 3.3,95 \% \mathrm{Cl} 1.1-9.6, \mathrm{p}=0.03)$.

CONCLUSION: In a series of consecutive hospitalized patients with COVID-19, Ivermectin was not associated with improved outcomes and Hydroxychloroquine may have resulted in a harmful effect.

KEYWORDS: Coronavirus. Hydroxychloroquine. Ivermectin. Prognosis.
\end{abstract}

\section{INTRODUCTION}

The pandemic associated with the severe acute respiratory syndrome coronavirus 2 (SARS-CoV-2) continues to impose an unprecedented burden on several governments, health systems, and scientific communities around the world. As of June 22, 2021, over 179.6 million global cases of coronavirus disease-2019 (COVID-19) had been reported with more than 3 million deaths, according to the World Health
Organization $(\mathrm{WHO})^{1}$. As the number continues to increase, the search for effective evidence-based interventions in both prevention and treatment also continues. Social distancing, personal protective equipment, and adequate hand sanitation are still the main preventive measures, whereas appropriate respiratory support, selective steroid therapy, and management of secondary complications remain the cornerstones of treatment ${ }^{2,3}$.

\footnotetext{
${ }^{1}$ Hospital Samaritano - Botafogo (RJ), Brazil.

2Universidade Federal do Rio de Janeiro, Instituto do Coração Edson Saad - Rio de Janeiro (RJ), Brazil.

${ }^{3}$ Universidade Federal do Estado do Rio de Janeiro, Departamento de Cirurgia Geral - Rio de Janeiro (RJ), Brazil.

*Corresponding author: betomf@terra.com.br

Conflicts of interest: the authors declare there are no conflicts of interest. Funding: this study is supported by the Samaritano Hospital, Botafogo, Rio de Janeiro, Brazil.

Received on July 13, 2021. Accepted on August 11, 2021.
} 
Several medications have emerged as potential treatments for COVID-19, though there is limited supportive evidence for safety and efficacy. Most interventions have been based on nonclinical studies, observational data, and personal opinions of health care professionals ${ }^{4,5}$. The antimalarial hydroxychloroquine (HCQ) and antiparasitic ivermectin (IVM) are still advocated by many physicians and government officials as effective options in this context, particularly when initiated during the earlier days of symptoms ${ }^{6}$. The accumulated experience with these medications in other clinical scenarios has created a perception of similar safety profiles when prescribed for COVID-19. Although recent randomized trials have demonstrated the lack of benefit associated with HCQ and IVM, they remain frequently utilized in many areas where COVID-19 cases are still uncontrolled, such as Brazil and India ${ }^{1,7,8}$. In this study, clinical outcomes associated with HCQ and/or IVM were evaluated in a series of hospitalized patients with COVID-19 from a single institution in Brazil.

\section{METHODS}

Consecutive patients with COVID-19 admitted between March 12 and July 8, 2020, were retrospectively analyzed using medical chart review. Only those with a positive polymerase chain reaction result for SARS-CoV-2 were included. Clinical and laboratory information were collected by four trained physicians utilizing a prespecified form with detailed instructions. The accuracy of data extraction was confirmed by a fifth physician by random evaluation of completed forms from all reviewers.

Patients were divided into four Groups based on the prescription of HCQ and IVM before or after hospitalization: no treatment (Group 0), IVM only (Group I), HCQ only (Group II), and HCQ and IVM (Group III). Treatment begins with the administration of at least one dose of IVM or HCQ after the beginning of COVID-19 symptoms. Baseline clinical and laboratory characteristics, in addition to in-hospital outcomes, were compared between the Groups. Adverse outcomes included intensive care unit (ICU) admission rate, mechanical ventilation (MV) requirement, and death.

For statistical analysis, Stata ${ }^{\circledR}$ version 11.0 software was used. Categorical variables were analyzed with $\chi^{2}$ and Fisher's exact tests. All continuous variables were non-normally distributed using Shapiro-Wilk test and were expressed as median and interquartile range (IQR) (25th-75th percentile). The collected data were evaluated by the Wilcoxon-Mann-Whitney and Kruskal-Wallis tests. To evaluate association between continuous variables and mortality, the graphical models were represented by predicted probability plots. Significant variables in the univariate analysis were included in a multivariate logistic regression model to determine independent predictors of death. A $p<0.05$ was considered significant. The study conforms to the guidelines of the Declaration of Helsinki and was approved by the hospital's ethics committee.

\section{RESULTS}

During the study period, 230 patients with confirmed COVID-19 who were admitted at our institution were included in the analysis. Patients were predominantly males with a median age of 68 years (IQR 54-82) and an elevated prevalence of hypertension and diabetes, despite a low frequency of underlying pulmonary disease and current or previous tobacco use. The median symptom duration before admission was 6 days (IQR 3-9), and overall oxygen saturation at room temperature was 93\% (IQR 91-96). Complete clinical and laboratory baseline characteristics are listed in Table 1 .

Table 1. Baseline characteristics according to treatment Group.

\begin{tabular}{|c|c|c|c|c|c|c|}
\hline \multirow[b]{2}{*}{ Baseline characteristics } & \multirow{2}{*}{$\begin{array}{l}\text { Total, } \\
n=230\end{array}$} & \multicolumn{4}{|c|}{ IVM and/or HCQ during hospitalization } & \multirow[b]{2}{*}{ p-value ${ }^{a}$} \\
\hline & & $\begin{array}{c}\text { No }(0) \\
n=81\end{array}$ & $\begin{array}{l}\text { IVM only } \\
\text { (I), } n=21\end{array}$ & $\begin{array}{l}\text { HCQ only } \\
\text { (II), } n=111\end{array}$ & $\begin{array}{l}\text { IVM+HCQ } \\
\text { (III), n=17 }\end{array}$ & \\
\hline Age, median (IQR), years & $68(54-82)$ & $77(61-87)$ & $68(56-79)$ & $63(50-74)^{c}$ & $76(62-83)$ & 0.003 \\
\hline Male, n (\%) & $132(57.4)$ & $40(49.4)$ & $13(61.9)$ & $69(62.2)$ & $10(58.8)$ & 0.34 \\
\hline BMI, median (IQR), kg/m² & $\begin{array}{c}26.4 \\
(23.9-30.1)\end{array}$ & $\begin{array}{c}25 \\
(22.9-28.2)\end{array}$ & $\begin{array}{c}26.9 \\
(24.8-32.0)^{c}\end{array}$ & $\begin{array}{c}28 \\
(24.9-30.3)^{c}\end{array}$ & $\begin{array}{c}28.6 \\
(23.8-30.9)\end{array}$ & 0.008 \\
\hline \multicolumn{7}{|l|}{ Medical history, $\mathrm{n}(\%)$} \\
\hline Hypertension & $119(51.7)$ & $45(55.6)$ & $12(57.1)$ & $54(48.7)$ & $8(47.1)$ & 0.73 \\
\hline Diabetes & $67(29.1)$ & $29(35.8)$ & $5(23.8)$ & $29(26.1)$ & $4(23.5)$ & 0.43 \\
\hline CVD & $34(14.8)$ & $16(19.8)$ & $3(14.3)$ & $14(12.6)$ & $1(5.9)$ & 0.38 \\
\hline
\end{tabular}


Table 1. Continuation.

\begin{tabular}{|c|c|c|c|c|c|c|}
\hline \multirow[b]{2}{*}{ Baseline characteristics } & \multirow{2}{*}{$\begin{array}{l}\text { Total, } \\
n=230\end{array}$} & \multicolumn{4}{|c|}{ IVM and/or HCQ during hospitalization } & \multirow[b]{2}{*}{ p-value } \\
\hline & & $\begin{array}{c}\text { No }(0), \\
n=81\end{array}$ & $\begin{array}{l}\text { IVM only } \\
(I), n=21\end{array}$ & $\begin{array}{l}\text { HCQ only } \\
\text { (II), } \mathrm{n}=111\end{array}$ & $\begin{array}{l}\text { IVM+HCQ } \\
\text { (III), } n=17\end{array}$ & \\
\hline Heart failure or LVD & $5(2.17)$ & $2(2.5)$ & 0 & $3(2.7)$ & 0 & 0.79 \\
\hline Asthma or COPD & $25(10.9)$ & $11(13.6)$ & $2(9.5)$ & $9(8.1)$ & $3(17.7)$ & 0.51 \\
\hline Cancer & $31(13.5)$ & $15(18.5)$ & $4(19.1)$ & $11(9.9)$ & $1(5.9)$ & 0.22 \\
\hline Current or prior tobacco use & $24(10.4)$ & $10(12.4)$ & $4(19.1)$ & $7(6.3)$ & $3(17.7)$ & 0.18 \\
\hline $\begin{array}{l}\text { Symptom duration before } \\
\text { admission, median (IQR), days }\end{array}$ & $6(3-9)$ & $7(3-9)$ & $7(5-10)$ & $6(3-8)$ & $6(5-10)$ & 0.21 \\
\hline $\begin{array}{l}\text { Oxygen saturation on ambient } \\
\text { air, median (IQR), \% }\end{array}$ & $93(91-96)$ & $94(91-96)$ & $94(91-96)$ & $93(90-95)$ & $92(90-95)$ & 0.50 \\
\hline Systolic BP, median (IQR), mm Hg & $\begin{array}{c}130 \\
(119-145) \\
\end{array}$ & $\begin{array}{c}130 \\
(119-146) \\
\end{array}$ & $\begin{array}{c}128 \\
(115-140) \\
\end{array}$ & $\begin{array}{c}132 \\
(120-145) \\
\end{array}$ & $\begin{array}{c}120 \\
(119-130)\end{array}$ & 0.29 \\
\hline \multicolumn{7}{|l|}{ Blood test, median (IQR) } \\
\hline Leukocyte count, cells $/ \mathrm{mm}^{3}$ & $\begin{array}{c}5905 \\
(4590-8290) \\
\end{array}$ & $\begin{array}{c}6140 \\
(4590-10110) \\
\end{array}$ & $\begin{array}{c}5850 \\
(4850-8350) \\
\end{array}$ & $\begin{array}{c}5800 \\
(4360-7860)\end{array}$ & $\begin{array}{c}6320 \\
(5140-8050)\end{array}$ & 0.75 \\
\hline Lymphocyte count, cells/mm³ & $\begin{array}{c}928 \\
(669-1250) \\
\end{array}$ & $\begin{array}{c}920 \\
(645-1282) \\
\end{array}$ & $\begin{array}{c}708 \\
(541-1028) \\
\end{array}$ & $\begin{array}{c}958 \\
(680-1250) \\
\end{array}$ & $\begin{array}{c}928 \\
(741-1115) \\
\end{array}$ & 0.54 \\
\hline Hemoglobin, mg/dL & $\begin{array}{c}13.4 \\
(12-14.6) \\
\end{array}$ & $\begin{array}{c}12.9 \\
(11.1-14.1) \\
\end{array}$ & $\begin{array}{c}14 \\
(11-14.6)^{c} \\
\end{array}$ & $\begin{array}{c}13.5 \\
(12.5-14.9) \\
\end{array}$ & $\begin{array}{c}13.2 \\
(12.3-14.6) \\
\end{array}$ & 0.015 \\
\hline Platelet count, $\times 10^{3} / \mathrm{mm}^{3}$ & $\begin{array}{c}177.5 \\
(144-233) \\
\end{array}$ & $\begin{array}{c}191 \\
(148-240)\end{array}$ & $\begin{array}{c}171 \\
(132-258) \\
\end{array}$ & $\begin{array}{c}174 \\
(138-219) \\
\end{array}$ & $\begin{array}{c}175 \\
(145-205) \\
\end{array}$ & 0.55 \\
\hline C-reactive protein, $\mathrm{mg} / \mathrm{mL}$ & $\begin{array}{c}6.65 \\
(3.3-14.3)\end{array}$ & $\begin{array}{c}6.1 \\
(2.4-14)\end{array}$ & $\begin{array}{c}6.2 \\
(4.8-13.2)\end{array}$ & $\begin{array}{c}7.7 \\
(3.3-15)\end{array}$ & $\begin{array}{c}7 \\
(4.7-14.3)\end{array}$ & 0.59 \\
\hline D-Dimer, ng/mL & $\begin{array}{c}778 \\
(457-1418) \\
\end{array}$ & $\begin{array}{c}877 \\
(550-1994) \\
\end{array}$ & $\begin{array}{c}795 \\
(486-1339) \\
\end{array}$ & $\begin{array}{c}629 \\
(415-1181) \\
\end{array}$ & $\begin{array}{c}807 \\
(505-1262) \\
\end{array}$ & 0.16 \\
\hline hs-Troponin I, pg/mL & $\begin{array}{c}11 \\
(11-24.5) \\
\end{array}$ & $\begin{array}{c}12 \\
(11-48) \\
\end{array}$ & $\begin{array}{c}11 \\
(11-15.5)^{c} \\
\end{array}$ & $\begin{array}{c}11 \\
(11-13)^{c} \\
\end{array}$ & $\begin{array}{c}11 \\
(11-12)^{c} \\
\end{array}$ & 0.04 \\
\hline Creatinine, mg/dL & $\begin{array}{c}0.9 \\
(0.7-1.1) \\
\end{array}$ & $\begin{array}{c}0.9 \\
(0.7-1.2) \\
\end{array}$ & $\begin{array}{c}0.9 \\
(0.8-1.0) \\
\end{array}$ & $\begin{array}{c}0.9 \\
(0.7-1.1) \\
\end{array}$ & $\begin{array}{c}1.0 \\
(0.6-1.2) \\
\end{array}$ & 0.99 \\
\hline $\begin{array}{l}\text { Total chest CT opacities, } \\
\text { median (IQR), }(\%)^{b}\end{array}$ & $\begin{array}{c}15.8 \\
(6.7-30.4) \\
\end{array}$ & $\begin{array}{c}14.8 \\
(4.4-31.9) \\
\end{array}$ & $\begin{array}{c}20.2 \\
(5.2-41.3) \\
\end{array}$ & $\begin{array}{c}15.9 \\
(9.2-27.7) \\
\end{array}$ & $\begin{array}{c}16.2 \\
(9.0-23.5) \\
\end{array}$ & 0.88 \\
\hline
\end{tabular}

Previous antithrombotics, n (\%)

\begin{tabular}{|c|c|c|c|c|c|c|}
\hline Antiplatelets & $35(15.2)$ & $17(21)$ & $4(19.1)$ & $11(9.9)$ & $3(17.7)$ & 0.14 \\
\hline Anticoagulants & $28(12.2)$ & $14(17.3)$ & $2(9.5)$ & $11(9.9)$ & $1(5.9)$ & 0.44 \\
\hline Azithromycin, n (\%) & $182(79.1)$ & $48(59.3)$ & $14(66.7)$ & $103(92.8)^{c}$ & $17(100)^{c}$ & $<0.001$ \\
\hline \multicolumn{7}{|l|}{ Hydroxychloroquine, n (\%) } \\
\hline Total & $128(55.7)$ & 0 & 0 & $111(100)$ & $17(100)$ & - \\
\hline First 7 days of symptoms & $79(34.3)$ & NA & NA & $68(61.3)$ & $11(64.7)$ & - \\
\hline \multicolumn{7}{|l|}{ Ivermectin, n (\%) } \\
\hline Total & $38(16.5)$ & 0 & $21(100)$ & 0 & $17(100)$ & - \\
\hline First 7 days of symptoms & $15(6.5)$ & NA & $8(38.1)$ & NA & $11(64.7)$ & - \\
\hline $\begin{array}{l}\text { Symptom duration before } \\
\text { treatment, median (IQR), days }\end{array}$ & $7(4-9)$ & NA & $7(5-10)$ & $6(3-8)$ & $6(5-10)$ & 0.21 \\
\hline
\end{tabular}

${ }^{a} p<0.05$ indicates statistical significance (bold values); ${ }^{b} n=200$; 'significant difference when compared to Group 0. BMI: body mass index; BP: blood pressure; COPD: chronic obstructive pulmonary disease; CT: computed tomography; CVD: cardiovascular disease; hs: high-sensitivity; HCQ: Hydroxychloroquine; IQR: interquartile range; IVM: Ivermectin; NA: not applicable. 
Of the 230 patients, 21 (9.1\%) received only IVM (Group I), 111 (48.2\%) were treated with HCQ (Group II), and 17 (7.4\%) were prescribed both drugs (Group III). The remaining $81(35.2 \%)$ patients did not receive any of the two medications (Group 0). The median age, body mass index (BMI), and clinical variables, such as symptom duration and oxygen saturation on ambient air, were similar among all Groups. Patients in Group 0 were significantly older and with a lower BMI. On admission, those who did not receive either IVM or HCQ presented with higher levels of troponin and lower hemoglobin values. The remaining laboratory parameters and pulmonary disease burden on chest computed tomography were not significantly different. Compared to Group 0 , the frequency of azithromycin use was significantly greater among patients in Groups II and III.

During the hospitalization period, 37 (16.1\%) patients died. The median length of stay was nine days (IQR: 5-20), 72 (31.3\%) patients required ICU admission, and 47 (20.4\%) were treated with MV. The combined outcome of death, ICU admission, and MV was significantly higher in Groups II and III compared to Group 0. Group III also presented the greatest mortality rate (35.3\%). Outcomes associated with each Group are represented in Figure 1A.

On admission, the predictors of subsequent in-hospital death in the univariate analysis included age, previous cardiovascular disease, symptom duration, oxygen saturation, systolic blood pressure, C-reactive protein, and D-dimer levels. When IVM and HCQ were added to the multivariate model, only age (OR 1.15, 95\%CI 1.1-1.2, p<0.001), HCQ (OR
3.3, 95\%CI 1.1-9.6, $\mathrm{p}=0.03$ ), and C-reactive protein (OR $1.1,95 \% \mathrm{CI} 1.0-1.2, \mathrm{p}=0.02)$ remained significantly associated with death. An inverse relationship was found between symptom duration before treatment initiation and death in Groups I, II, and III (Figure 1B).

\section{DISCUSSION}

In this single-center observational study, neither IVM nor HCQ was associated with improved outcomes among hospitalized patients with COVID-19. As randomized trials continue to be published in this field, it remains important to reassess the results of practice patterns that have been adopted since the initial stages of the pandemic. Similarly to IVM and HCQ, many other interventions such as zinc, azithromycin, and favipiravir have been advocated for early treatment of the disease despite the lack of supportive clinical evidence. Recommendations are largely based on in vitro studies, observational data, and personal opinion, with subsequent extrapolation of theoretical clinical benefits ${ }^{4,9}$.

Almost 18 months after the beginning of the pandemic, a variety of randomized trials have studied HCQ in different clinical scenarios and disease severities. Reis et al. randomized 685 outpatients in the first week of symptoms to either HCQ, lopinavir-ritonavir, or placebo and evaluated the effects of each intervention on admission rates or death. The study was stopped early after the first interim analysis for futility of both treatment arms. In addition, no differences were found in virological clearance rates or time to symptom
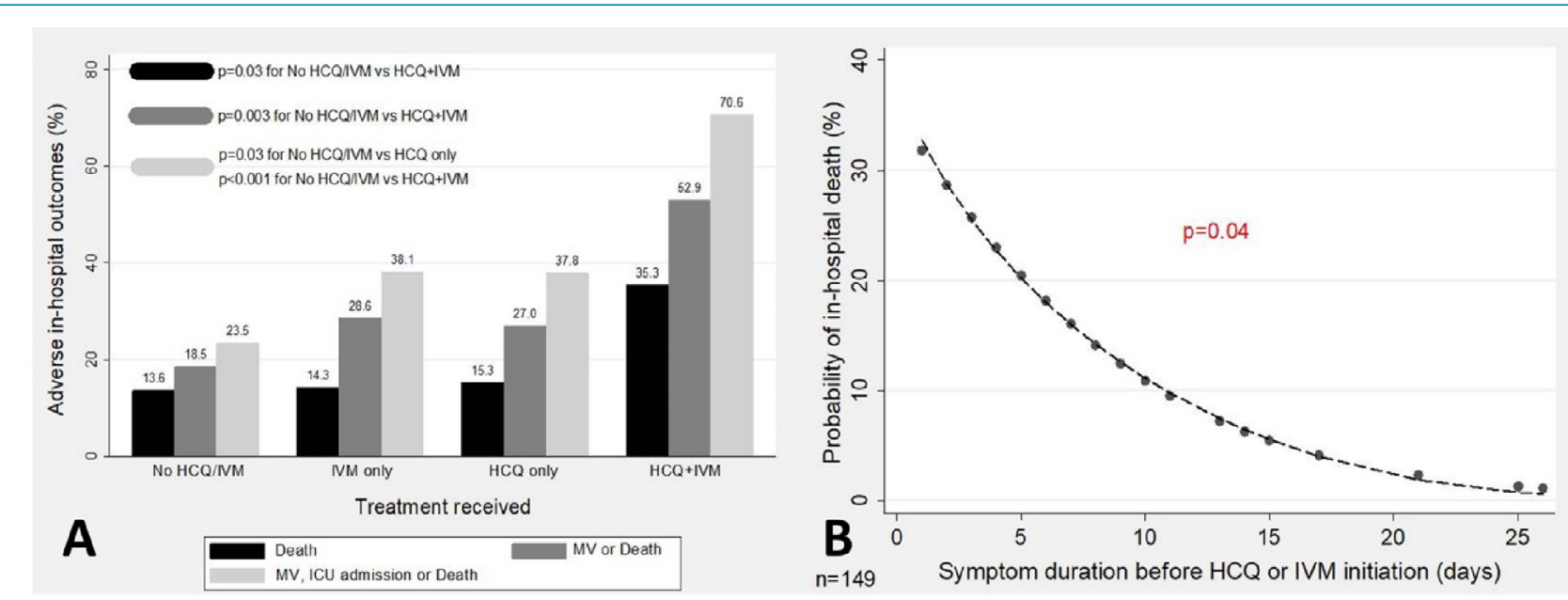

HCQ: Hydroxychloroquine; ICU: intensive care unit; IVM: Ivermectin; MV: mechanical ventilation.

Figure 1. (A) In-hospital outcomes associated with hydroxychloroquine and ivermectin use in patients with COVID-19. (B) Relationship between symptom duration before Hydroxychloroquine and/or Ivermectin prescription and subsequent probability of death. 
resolution ${ }^{10}$. These results contradict the hypothesis that HCQ may be effective in the early stages of the infection, by limiting viral replication.

In a randomized trial among hospitalized patients with severe disease, Réa-Neto et al. reported poorer outcomes among those treated with HCQ. Similarly to our results, a high rate of azithromycin use was also seen in the intervention arm (96.2\%). Patients who received HCQ were at increased risk of developing a worsening in clinical status, renal dysfunction, or requiring $\mathrm{MV}^{11}$. A recent meta-analysis of 28 randomized clinical trials evaluating mortality outcomes associated with HCQ has supported these results, suggesting that HCQ is associated with increased death rates in patients with COVID-19 12 .

Fewer randomized trials evaluating IVM in COVID-19 have been reported, although small publications with significant methodological issues are presently available ${ }^{2}$. A trial published by López-Medina et al. addressed many of the previous limitations and analyzed the effect of IVM on symptom resolution among 400 outpatients with COVID-19. A 5-day course of IVM was not associated with better outcomes, although treatment was begun on the first week of symptoms ${ }^{13}$. As such, IVM is currently recommend by many infectious disease organizations as an option for COVID-19 only within the scope of a clinical trial ${ }^{2,3}$.

Our study demonstrates comparable results, though outside the boundaries of a clinical trial. Despite the greater median age, patients who did not receive IVM or HCQ during hospitalization (Group 0) are much better than those in Groups I, II, and III. Notably, death, ICU admission, and MV rates were greatest among those treated with HCQ (Groups II and III), suggesting a neutral effect of isolated IVM use, but a potentially detrimental impact of HCQ, especially when combined with IVM. Even in the multivariate analysis, HCQ persisted as an independent predictor of in-hospital death. The potential adverse cardiovascular and renal effects promoted by HCQ should be appreciated and may contribute to clinical deterioration ${ }^{14}$. Symptom duration before treatment initiation did not improve the results and even demonstrated an inverse relationship with subsequent mortality.
This study has limitations. The retrospective and single-center nature of the results should be regarded as hypothesis generating and is not free from potential biases. The data were extracted since admissions, which occurred in the beginning of the pandemic in Brazil, when treatments of uncertain benefit were more likely to be offered to sicker patients. Nevertheless, when adjusting the analysis to other determinants of clinical severity, HCQ remained associated with death. Among those in Groups I, II, and III who were admitted to the ICU and required $\mathrm{MV}$, it was not established if the medications were begun after the end points occurred. Still, median symptom duration upon admission was similar to the time of disease progression before treatment initiation, suggesting that the drugs were primarily prescribed earlier than the evaluated outcomes. Finally, the influence on outcomes of other potential interventions, such as antibiotics, tocilizumab, and corticosteroids, which may have been utilized during hospitalization, must be considered.

\section{CONCLUSIONS}

During any pandemic, despite the eagerness to discover an effective and safe treatment in a timely manner, the standards and processes of evidence-based medicine must be followed. Several treatments for COVID-19 have been widely adopted without regarding the necessary steps of clinical research. In the current study, IVM was not associated with improved outcomes and HCQ was related to increased mortality rates. In the future, results of randomized controlled trials should be considered before the adoption of new interventions of unknown clinical benefit, especially when potential harms cannot be excluded.

\section{AUTHORS' CONTRIBUTIONS}

RMF: Conceptualization, Data curation, Formal analysis, Writing - review \& editing. RWB: Supervision, Data curation, Formal analysis. PPNS: Data curation, Writing - review \& editing. JMF: Conceptualization, Writing - review \& editing. RACL: Conceptualization, Supervision, Writing - review \& editing.

\section{REFERENCES}

1. World Health Organization. WHO Coronavirus (COVID-19) Dashboard [internet]. Geneva: World Health Organization; 2021. [cited on May 26, 2021]. Available from: https://covid19. who.int/

2. Bhimraj A, Morgan RL, Shumaker AH, Lavergne $V$, Baden $L$, Cheng VCC, et al. IDSA guidelines on the treatment and management of patients with COVID-19[internet].
Virgínia: Infectious diseases society of America; 2021. [cited on Jun. 22, 2021]. Available from: https://www.idsociety. org/practice-guideline/covid-19-guideline-treatment-andmanagement/

3. Coronavirus Disease 2019 (COVID-19) Treatment guidelines [internet]. Bethesda (MD): National Institutes of Health (US); 2021. PMID: 34003615 
4. McCullough P, Kelly R, Ruocco G, Lerma E, Tumlin J, Wheelan $K R$, et al. Pathophysiological basis and rationale for early outpatient treatment of SARS-CoV-2 (COVID-19) infection. Am J Med. 2021;134(1):16-22. https://doi.org/10.1016/j. amjmed.2020.07.003

5. Gupta D, Sahoo A, Singh A. Ivermectin: potential candidate for the treatment of Covid 19. Braz J Infect Dis. 2020;24(4):369-71. Braz J Infect Dis. https://doi.org/10.1016/j.bjid.2020.06.002

6. Hallal P. SOS Brazil: science under attack. The Lancet. 2021;397(10272):373-4. https://doi.org/10.1016/S01406736(21)00141-0

7. Cardoso CRB, Fernandes APM, Santos IKFM. What happens in Brazil? A pandemic of misinformation that culminates in an endless disease burden. Rev Soc Bras Med Trop. 2021;54. https://doi.org/10.1590/0037-8682-0713-2020

8. Vora A, Arora VK, Behera D, Tripathy SK. White paper on Ivermectin as a potential therapy for COVID-19. Indian J Tuberc. 2020;67(3):448-51. https://doi.org/10.1016/j.jitb.2020.07.031

9. Ali MJ, Hanif M, Haider MA, Ahmed MU, Sundas FNU, Hirani A, et al. Treatment options for COVID-19: a review. Front Med (Lausanne). 2020;7:480. https://doi.org/10.3389/ fmed.2020.00480
10. Reis G, Silva EM, Silva DM, Thabane L, Singh G, Park JJH, et al. Effect of early treatment with Hydroxychloroquine or Lopinavir and Ritonavir on risk of hospitalization among patients with COVID-19. JAMA Netw Open. 2021;4(4):e216468. https:// doi.org/10.1001/jamanetworkopen.2021.6468

11. Réa-Neto Á, Bernardelli R, Câmara B, Reese F, Queiroga $M$, Oliveira M. An open-label randomized controlled trial evaluating the efficacy of chloroquine/hydroxychloroquine in severe COVID-19 patients. Sci Rep. 2021;11(1):9023. https:// doi.org/10.1038/s41598-021-88509-9

12. Axfors $C$, Schmitt $A$, Janiaud P, van't Hooft J, Abd-Elsalam S, Abdo EF, et al. Mortality outcomes with hydroxychloroquine and chloroquine in COVID-19 from an international collaborative meta-analysis of randomized trials. Nat Commun. 2021;12(1):2349. https://doi.org/10.1038/s41467-021-22446-z

13. López-Medina E, López P, Hurtado IC, Dávalos DM, Ramirez $O$, Martínez $E$, et al. Effect of Ivermectin on time to resolution of symptoms among adults with mild COVID-19. JAMA. 2021;325(14):1426. https://doi.org/10.1001/jama.2021.3071

14. Alanagreh L, Alzoughool F, Atoum M. Risk of using hydroxychloroquine as a treatment of COVID-19. Int J Risk Saf Med. 2020;31(3):111-6. https://doi.org/10.3233/JRS-200024 